\title{
Clinical features and imaging findings in a case of Capgras syndrome
}

This article was published in the following Dove Press journal:

Neuropsychiatric Disease and Treatment

5 August 2013

Number of times this article has been viewed

\author{
Maria Luca' \\ Andrea Bordone' \\ Antonina Luca ${ }^{2}$ \\ Andrea Patti' \\ Giuseppe Sortino ${ }^{3}$ \\ Carmela Calandra' \\ 'Department of Medical and \\ Surgery Specialties, Psychiatry Unit, \\ ${ }^{2}$ Department GF Ingrassia, Section \\ of Neuroscience, ${ }^{3}$ Department of \\ Diagnostic Imaging, Radiology Unit, \\ University Hospital Policlinico- \\ Vittorio Emanuele, Catania, Sicily, Italy
}

\begin{abstract}
Capgras syndrome consists of the delusional belief that a person or persons have been replaced by doubles or impostors. It can occur in the context of both psychiatric and organic illness, and seems to be related to lesions of the bifrontal and right limbic and temporal regions. Indeed, magnetic resonance imaging has revealed brain lesions in patients suffering from Capgras syndrome. This case study reports the findings of a thorough diagnostic evaluation in a woman suffering from Capgras syndrome and presenting with the following clinical peculiarities: obsessive modality of presentation of the delusional ideation, intrusiveness of such ideation (that even disturbed her sleep), as well as a sense of alienation and utter disgust towards the double. These characteristics bring to mind the typical aspects of obsessive-compulsive disorder. Neuroanatomic investigation, through magnetic resonance imaging, performed on this patient showed alteration of the bilateral semioval centers, which are brain regions associated with the emotion of disgust and often show alterations in subjects suffering from obsessive-compulsive disorder. Hence, neuroimaging allows researchers to put forward the hypothesis of a common neuroanatomic basis for Capgras syndrome and obsessive-compulsive disorder, at least for cases in which the delusional ideation is associated with deep feelings of disgust and presents with a certain pervasiveness.
\end{abstract}

Keywords: Capgras syndrome, magnetic resonance imaging, electroencephalography, obsessive-compulsive disorder, semioval centers

\section{Introduction}

Delusional misidentification syndromes are characterized by an interesting psychopathologic phenomenon in which patients misidentify familiar persons, objects, or themselves, believing that they have been replaced or transformed. ${ }^{1,2}$ The correct classification of these diseases is still unclear; within the Diagnostic and Statistical Manual of Mental Disorders, Fourth Edition (DSM-IV), ${ }^{3}$ they could be included among the broader category of delusional disorders but, as reported in the literature, there is not always a concordance between the symptoms presented by the patients and the rigid diagnostic categories. ${ }^{4}$ Delusional misidentification syndromes can occur in the case of idiopathic psychiatric illness as well as in the case of diffuse or focal brain damage, and are characterized by a pattern of neuropsychologic impairments (particularly affecting memory and perception) which are not indicators of the selectivity of these delusional phenomena. In fact, other variables, such as premorbid psychopathology and motivation, may be important in determining which patients are more vulnerable to developing delusional misidentification syndromes. ${ }^{5}$
Correspondence: Carmela Calandra Department of Medical and Surgery Specialties, Psychiatry Unit of the University Hospital Policlinico-Vittorio Emanuele, Via S Sofia 78, Catania, Sicily 95100 , Italy

Tel +390953782636

Fax +390953782636

Email c.calandra@unict.it 
Among the delusional misidentification syndromes, Capgras syndrome is the most common and consists of the delusional belief that a person or persons have been replaced by doubles or impostors. ${ }^{6}$ In 1923, this syndrome was described by Capgras and Reboul-Lachaux, and was originally termed "illusion des sosies". ${ }^{7}$ The Capgras delusion can be considered a symptom occurring in adults and in children ${ }^{8}$ in the context of both psychiatric and organic illness. ${ }^{9}{ }^{910}$ As a matter of fact, it can be associated with other psychiatric conditions, especially schizophrenia. ${ }^{11}$ It can present as a complication of neurodegenerative disorders (such as multiple sclerosis and Alzheimer's disease) ${ }^{12,13}$ and infective conditions, ${ }^{10}$ or can even be a manifestation of drug toxicity. ${ }^{14}$ Moreover, it seems to be related to lesions of bifrontal and right limbic and temporal regions. ${ }^{9}$ Indeed, magnetic resonance imaging has revealed brain lesions in patients suffering from Capgras syndrome affecting in particular the frontal and subcortical regions. ${ }^{15,16}$ This delusion could also be due to a disconnection between the frontal lobes and right temporolimbic regions. Hence, it is impossible to link information regarding identification of the person and the emotions arising from such identification. ${ }^{6}$ Psychodynamic explanations for the occurrence of such a particular delusion have been provided by some authors, ${ }^{17,18}$ even though these explanations have been regarded as insufficient. ${ }^{19}$ From a psychodynamic point of view, the Capgras delusion arises from an altered affective response and leads to intolerable ambivalent feelings which are neutralized by "creation" of doubles. ${ }^{17,18}$ This case study reports the findings of thorough diagnostic evaluation in a woman suffering from Capgras syndrome.

\section{Case report}

A 53-year-old Caucasian woman was referred to our Psychiatry Unit for hospitalization by her general practitioner. Anamnestic data collection revealed that the patient had had a difficult adolescence, due to the fact that her father had had a mistress and suffered from pathologic gambling. Notwithstanding, she had not experienced any previous psychopathologic problems in the past. She was a housewife with two daughters, and the eldest daughter had always been in conflict with her mother. On the day of her admission to hospital, the patient had a fatuous expression, seemed apathetic, and was suffering from considerable psychomotor retardation. She was distrustful of other patients because they were "too intrusive". However, when approaching other patients, she showed a childish attitude and was disrespectful of conventional interpersonal distances. The patient had the delusional belief that her eldest daughter, whom she thought had disappeared for 12 months, had been replaced by an impostor. In fact, the previous year the patient's daughter had left her house without telling her mother. The patient tried to get in touch with her, and the girl answered the phone saying that she was at work. Because her workplace was quite far off from her house, the patient thought that it was not possible for her daughter to arrive at work in such a short time. Hence, she believed that the person she had spoken to over the phone was an impostor who was replacing the daughter whom she thought had disappeared.

Her delusional belief was characterized by incorrigibility and unwarranted subjective conviction. The patient had two "proofs" to justify her belief: the distance of the workplace and the impostor's makeup, which was heavier than that worn by her daughter.

The patient was experiencing not only the tragedy of a mother who had lost her daughter, but also the frustration of continuous deception by the "double"/impostor. Indeed, the patient thought that the "double" was imitating her daughter's way of speaking so as to convince her (the patient) that she (the "double") was her daughter. The patient had no idea where her daughter could be. However, she did nothing to find out where she was. In addition, even though she considered the impostor to be a menacing presence, the patient had a passive attitude towards the impostor, and treated her with indifference. Her mood was deflected owing to her daughter's disappearance. Obviously, the patient had no insight into her illness. The Capgras delusion was the only unusual belief presented by this patient, who did not show any other psychotic symptoms. The clinical picture of this patient was peculiar: she was tormented by the thought of the "double" who, in addition, provoked a feeling of disgust. This feeling was caused by the fact that the "double" treated the patient in a confidential way in order to deceive her without feeling any real affection. This thought, which was particularly intrusive, caused her considerable distress and even disturbed her sleep; almost every night, she had difficulty in falling asleep at the thought of the painful condition of deception that she had to endure. In addition, this delusional belief was presented to the medical interviewers in an obsessive way, with perseveration regarding the subject (she constantly repeated that the woman was not her daughter), and the thought content restricted to it. The story about her daughter was the answer to simple questions that had nothing to do with the topic. The intrusive thoughts pertaining to her daughter's disappearance and to the impostor were always present and did not fluctuate much over time.

General physical examination was within normal limits. She did not drink alcohol or coffee, and did not use any illicit 
or recreational drugs. The Mini-Mental State Examination $(\mathrm{MMSE})^{20}$ was $27 / 30$, indicating normal cognition. Items of the MMSE that the patient was less able to complete pertained to calculation and to short-term and long-term memory. The Structured Clinical Interview for DSM-IV Axis II Personality Disorders ${ }^{21}$ indicated an unspecified personality disorder, with a preponderance of paranoid and obsessive-compulsive personality traits. The electroencephalogram was characterized by background alpha activity and rapid rhythms in the frontocentral regions, bilaterally, as shown in Figure 1. Magnetic resonance imaging (images obtained through fluidattenuated inversion recovery, spin echo, and turbo field echo techniques, diffusion weighted in axial, sagittal, and coronal planes) showed moderate lesions in the frontal subcortical white matter and in the semioval centers on both sides. In particular, in long repetition time sequences, these cerebral areas showed hyperintensities compatible with a picture of gliosis, as shown in Figure 2.

\section{Discussion}

The identification of an object implies an unconscious mental representation made available to the conscious part of the mind. The perception of an object is automatically connected to an emotion, produced in an unconscious way. In the abovementioned case, the cognitive unconsciousness of the patient processed the information, reaching erroneous conclusions regarding her daughter's identity. ${ }^{22}$ The cognitive models of face processing involve two stages: recognition of the face and generation of an affective response to the familiar face. ${ }^{23}$ Ellis and Young ${ }^{24}$ have suggested considering Capgras syndrome as the "mirror image" of prosopagnosia; in patients with Capgras syndrome, there is an inability to associate an emotional content with the recognized visual image, while in those with prosopagnosia, emotional identification is intact and the visual one is damaged. ${ }^{24,25}$

From a psychodynamic point of view, one could put forward the hypothesis that the negative emotions linked to the conflicting relationship with her daughter were neutralized by the patient through the creation of a "double" who could be hated openly, and toward whom she could show feelings of disgust. The clinical picture of the patient presented some peculiarities, such as the considerable psychomotor retardation, fatuous expression, and childish way of relating to others. These characteristics led us to suspect a

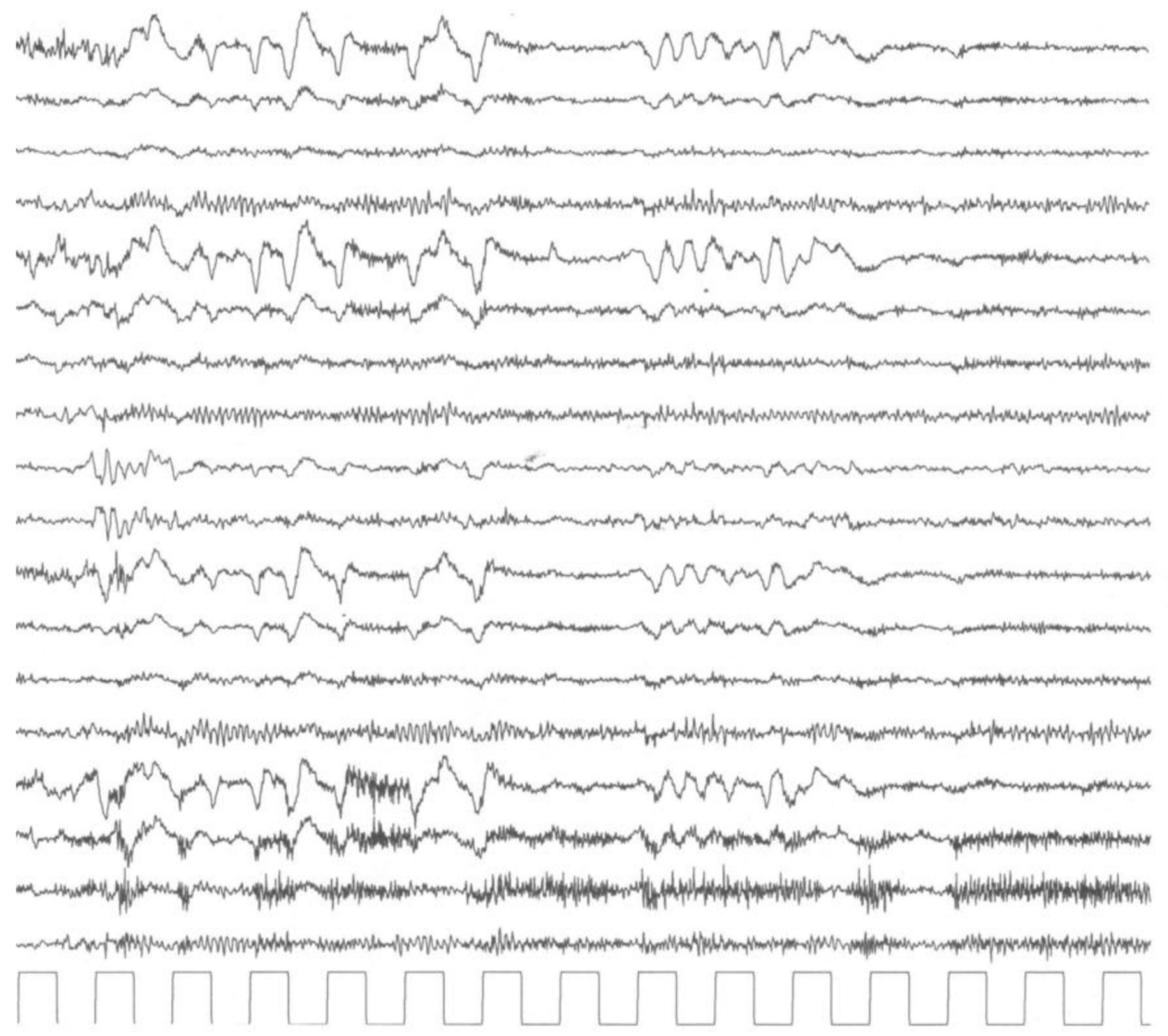

Figure I A portion of the electroencephalogram report is shown. Note the presence of background alpha activity and rapid rhythms on frontocentral regions, bilaterally. 


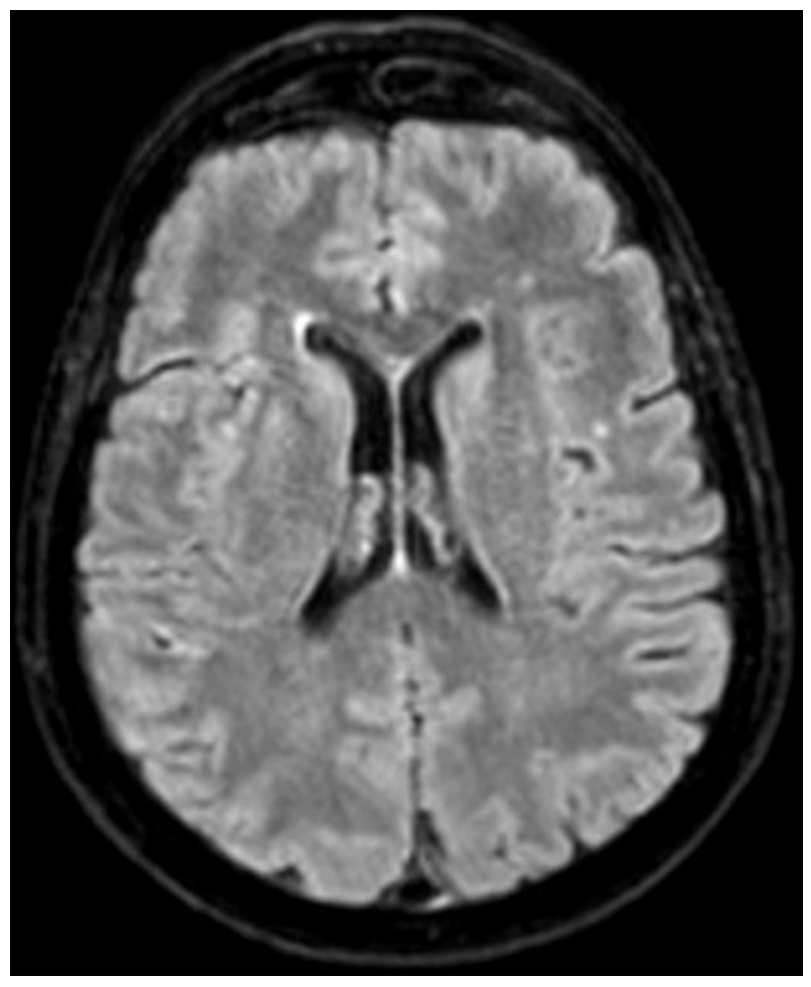

Figure 2 An Axial fluid-attenuated inversion recovery image obtained by magnetic resonance imaging (MRI) is reported. Note the moderate lesions in the frontal subcortical white matter and in semi oval centres of both sides.

dementia status, also considering the well known association between Capgras syndrome and dementia, ${ }^{26}$ but our suspicion was not confirmed on the MMSE. In addition, some aspects of the patient's disorder reminded us of the typical characteristics of obsessive-compulsive disorder, ie, the obsessive modality of presentation of delusional ideation, the intrusiveness of this ideation (that even disturbed her sleep), as well as a sense of alienation and utter disgust toward the impostor. However, in this case, the patient's thoughts were egosyntonic, being related to her delusional belief that the daughter had disappeared, so the patient did not try to suppress them. It has been shown that the emotion of disgust itself is a fundamental aspect of obsessive-compulsive disorder. ${ }^{27}$ Moreover, in a case of obsessive-compulsive disorder, a nondelusional variant of Capgras syndrome characterized by doubts regarding the substitution by doubles has been reported in literature. ${ }^{28}$ Another study of cases of delusional misidentification syndromes in subjects suffering from obsessive-compulsive disorder suggested that these syndromes could be the result of an association between obsessive fears and pre-existing cognitive deficits. ${ }^{29}$ We know from the literature that Capgras syndrome is associated with organic illness in up to $40 \%$ of cases. ${ }^{5}$ In our patient, both electroencephalography and magnetic resonance imaging showed alterations of an organic nature. Although several studies have correlated frontal and subcortical brain lesions with Capgras syndrome, ${ }^{15,16}$ to date there has been limited investigation of the correlation between specific cerebral areas and this peculiar delusional syndrome. The neuroanatomic investigation, through magnetic resonance imaging, performed on this patient showed hyperintensities in the frontal subcortical white matter and in the semioval centers on both sides, compatible with a picture of gliosis, thus indicating an alteration affecting these areas. The specific alteration of the bilateral semioval centers in Capgras syndrome is an interesting finding which, to the best of our knowledge, is new in the literature. These data encourage some speculation. The semioval centers are brain regions associated with the emotion of disgust and are often altered in subjects suffering from obsessive-compulsive disorder, ${ }^{30}$ which is notoriously highly sensitive to disgust. ${ }^{31}$ Hence, this may be the first time that neuroimaging has allowed researchers to put forward the hypothesis of a common neuroanatomic basis for Capgras syndrome and obsessive-compulsive disorder, which could provide an explanation for the overlap of clinical characteristics between these two disorders (at least for cases in which the delusional ideation is associated with deep feelings of disgust and shows a certain pervasiveness). Some authors have even wondered if delusional misidentification syndromes are nothing but an unusual presentation of psychiatric disorders already considered in the DSM-IV., Indeed, there is still a lot to investigate with regard to the Capgras delusion, a phenomenon that is both fascinating and complex. Hence, research should be extended in order to provide a response to the many open questions on this subject.

\section{Disclosure}

The authors report no conflicts of interest in this work.

\section{References}

1. Christodoulou GN. Delusional Misidentification Syndromes. Basel, Switzerland: Karger; 1986.

2. Jocic Z. Delusional misidentification syndromes. Jefferson Journal of Psychiatry. 1992;10:4.

3. American Psychiatric Association. Diagnostic and Statistical Manual of Mental Disorders Text Revision (DSM-IV-TR). 4th ed. Washington, DC: American Psychiatric Association; 2002.

4. Atta K, Forlenza N, Gujski M, Hashmi S, Isaac G. Delusional misidentification syndromes: separate disorders or unusual presentations of existing DSM-IV categories? Psychiatry (Edgmont). 2006;3:56-61.

5. Feinberg TE, Roane DM. Delusional misidentification. Psychiatr Clin North Am. 2005;28:665-683.

6. Madoz-Gúrpide A, Hillers-Rodríguez R. Capgras delusion: a review of aetiological theories. Rev Neurol. 2010;50:420-430. Spanish.

7. Capgras J, Reboul-Lachaux J. L'illusion des sosies dans un délire systématisé chronique. [The illusion of doubles in chronic systematized delusions]. Bull Soc Clin Med Ment. 1923;11:6-16. French. 
8. Mazzone L, Armando M, De Crescenzo F, Demaria F, Valeri G, Vicari S. Clinical picture and treatment implication in a child with Capgras syndrome: a case report. J Med Case Rep. 2012;6:406.

9. Hillers Rodríguez R, Madoz-Gúrpide A, Tirapu Ustárroz J. Capgras syndrome: a proposal of neuropsychological battery for assessment. Rev Esp Geriatr Gerontol. 2011;46:275-280. Spanish.

10. Salviati M, Bersani FS, Macrì F, et al. Capgras-like syndrome in a patient with an acute urinary tract infection. Neuropsychiatr Dis Treat. 2013;9:139-142.

11. Silva JA, Leong GB. The Capgras syndrome in paranoid schizophrenia. Psychopathology. 1992;25:147-153.

12. Sharma A, Garuba M, Egbert M. Capgras syndrome in a patient with multiple sclerosis: a case report. Prim Care Companion J Clin Psychiatry. 2009;11:274.

13. Fischer C, Keeler A, Fornazzari L, Ringer L, Hansen T, Schweizer TA. A rare variant of Capgras syndrome in Alzheimer's disease. Can J Neurol Sci. 2009;36:509-511.

14. Canagasabey B, Katona CL. Capgras syndrome in association with lithium toxicity. Br J Psychiatry. 1991;159:879-881.

15. Paillère-Martinot ML, Dao-Castellana MH, Masure MC, Pillon B, Martinot JL. Delusional misidentification: a clinical, neuropsychological and brain imaging case study. Psychopathology. 1994;27:200-210.

16. Lewis SW. Brain imaging in a case of Capgras' syndrome. Br J Psychiatry. 1987;150:117-121.

17. Fishbain DA, Schiffman J. The daughter as the principal "double" in a Capgras' syndrome: psychodynamic correlates. Am J Psychother. 1986;40:607-611.

18. O'Reilly R, Malhotra L. Capgras syndrome - an unusual case and discussion of psychodynamic factors. Br J Psychiatry. 1987;151: 263-265.

19. Sinkman AM. The Capgras delusion: a critique of its psychodynamic theories. Am J Psychother. 1983;37:428-438.

20. Folstein MF, Folstein SE, McHugh PR. "Mini-mental state". A practical method for grading the cognitive state of patients for the clinician. J Psychiatr Res. 1975;12:189-198.
21. First MB, Gibbon M, Spitzer RL, Williams JBW, Benjamin LS. Structured Clinical Interview for DSM-IV Axis II Personality Disorders, (SCID-II). Washington DC: American Psychiatric Press Inc; 1997.

22. Kihlstrom JF. The cognitive unconscious. Science. 1987;237: 1445-1452.

23. Breen N, Caine D, Coltheart M. Models of face recognition and delusional misidentification: a critical review. Cogn Neuropsychol. 2000;17:55-71.

24. Ellis HD, Young AW. Accounting for delusional misidentifications. $\mathrm{Br}$ J Psychiatry. 1990;157:239-248.

25. Ellis HD, Young AW, Quayle AH, De Pauw KW. Reduced autonomic responses to faces in Capgras delusion. Proc Biol Sci. 1997;264: 1085-1092.

26. Tsai SJ, Hwang JP, Yang CH, Liu KM, Lo Y. Capgras' syndrome in a patient with vascular dementia: a case report. Kaohsiung J Med Sci. 1997; 13:639-642.

27. Berle D, Phillips ES. Disgust and obsessive-compulsive disorder: an update. Psychiatry. 2006;69:228-238.

28. Stein RM, Lipper S. An obsessional variant of Capgras symptom: a case report. Bull Menninger Clin. 1988;52:52-57.

29. Melca IA, Rodrigues CL, Serra-Pinheiro MA, et al. Delusional misidentification syndromes in obsessive-compulsive disorder. Psychiatr Q. 2013;84:175-181.

30. Nakamae T, Narumoto J, Shibata K, et al. Alteration of fractional anisotropy and apparent diffusion coefficient in obsessive-compulsive disorder: a diffusion tensor imaging study. Prog Neuropsychopharmacol Biol Psychiatry. 2008;32:1221-1226.

31. Lawrence NS, An SK, Mataix-Cols D, Ruths F, Speckens A, Phillips ML. Neural responses to facial expressions of disgust but not fear are modulated by washing symptoms in OCD. Biol Psychiatry. 2007;61:1072-1080
Neuropsychiatric Disease and Treatment

\section{Publish your work in this journal}

Neuropsychiatric Disease and Treatment is an international, peerreviewed journal of clinical therapeutics and pharmacology focusing on concise rapid reporting of clinical or pre-clinical studies on a range of neuropsychiatric and neurological disorders. This journa is indexed on PubMed Central, the 'PsycINFO' database and CAS

\section{Dovepress}

The manuscript management system is completely online and includes a very quick and fair peer-review system, which is all easy to use. Visit http://www.dovepress.com/testimonials.php to read real quotes from published authors. 